\title{
Student Editorial Board for Volume 24
}

David Battin, Department of Human Development, Cornell University

Garth Coleman, Penetanguishene Mental Health Center

Jessica Consineau, College of Law, University of Arizona

Kevin Douglas, Department of Psychology, Fraser University

Eric Elbogen, Law/Psychology Program, University of Nebraska

Leslie Ellis, Northwestern University Law School

Lynn Garriocj, Department of Psychology, University of Victoria

Simona Ghetti, Department of Psychology, University of California

Livia L. Gilstrap, Department of Human Development, Cornell University

Amy Hackney, Department of Psychology, Saint Louis University

Ivan Haskell, Department of Psychology, University of South Carolina

Heather Hyme, Department of Psychology, Florida State University

Karen Kadela, Department of Psychology, Saint Louis University

Marc Klippenstine, Department of Psychology, York University

Daniel Krauss, Department of Psychology, University of Arizona

Maria Kriukova, Department of Psychology, Florida International University

Tim Lavery, Department of Criminal Justice, University of Illinois-Chicago

Cala Leheny, School of Law, Villanova Law School

Dorothy Marsil, Department of Psychology, University of Tennessee at

Chattanooga

Dawn McQuiston, Criminal Justice Program, University of Texas El Paso

Christian Meissner, Department of Psychology, Florida State University

Benjamin Morasco, Department of Psychology, Saint Louis University

Nicole Mott, Division of Criminal Justice, University of Delaware

Denise Mumley, Department of Psychiatry, University of Massachusetts Medical

School

Deb Oswald, Department of Psychology, Saint Louis University

Ernest Park, Department of Psychology, Michigan State University

Kim Picarello, School of Law, Villanova Law School

Shannon Rauch, Department of Psychology, Saint Louis University

Melanie Rogers, Department of Psychology, City University of New York

Aaron Rudnicki, Department of Psychology, University of Illinois-Chicago

Melinda G. Schmidt, Department of Psychology, University of Virginia

Dan Seagrave, Department of Psychiatry, University of Massachusetts Medical

School

Jennifer Shaffer, Department of Sociology, Pennsylvania State University 
Colleen Sinclair, Department of Psychology, University of Minnesota Allison Smith, Department of Psychology, University of Colorado at Colorado Springs

Samuel R. Sommers, Department of Psychology and School of Law, University of Michigan

Terri Stewart, Department of Psychology, University of Kentucky

Lisa Strohman, Law-Psychology Program, Hahnemann University

Lisa Strohman, School of Law, Villanova Law School

Laura Warren, Department of Psychology, Saint Louis University

Stephanie Weeks, Department of Psychology, North Carolina State University Ryan J. Winter, Department of Psychology, City University of New York 